\title{
Travel vaccines: Update for Canadian pharmacists
}

\author{
Christina Bascom, BScPharm, DTM (RCPSGlasg) iD
}

\section{Introduction}

Pretravel health assessments extend beyond vaccines, yet these play an integral role. Canadians made 31.3 million overnight departures abroad in 2016, and with recent expansion of pharmacists' authorization to administer vaccines across Canada, pharmacists with advanced training in travel medicine are well suited to fill a gap in providing guidance on safe and healthy travel practices, including administration of vaccines and personal protective measures (including personal safety, food and water precautions and bite avoidance). ${ }^{1-4}$ Community pharmacists without specialized training can proactively inquire with patients about upcoming travel and offer to review and administer commonly recommended travel vaccines (or complete a vaccine series). They should, however, refer travellers with more complex itineraries (i.e., nonresort travel) to a specialized travel clinic. By being proactive, pharmacists can ensure adequate dosing prior to departure and/or be able to seek alternate options in the event of vaccine unavailability.

Canadian travel clinics face many challenges, particularly related to vaccine shortages, but pharmacists who strive to maintain a high level of competency in travel health and vaccination can alleviate the impact these challenges could have on travellers' health. ${ }^{3-5}$ This article will focus on recent updates and challenges regarding commonly recommended travel vaccines, including those for travellers' diarrhea, cholera, hepatitis A and B, typhoid, Japanese encephalitis, rabies, meningococcal meningitis and yellow fever, and are summarized in Table 1.

\section{Travellers' diarrhea and cholera}

Travellers' diarrhea (TD), affecting $30 \%$ to $70 \%$ of travellers, is the most common health complaint for travellers, and risks correlate strongly to destination, duration and type of travel. ${ }^{6}$ The most common causes of TD are bacterial (80\%-90\%), with enterotoxigenic Escherichia coli (ETEC) being the predominant pathogen in $25 \%$ to $50 \%$ of all tested TD cases. ${ }^{7,8} \mathrm{TD}$ is defined as 3 or more unformed stools in 24 hours and is usually mild and self-limiting. ${ }^{7,9}$

The heat-labile enterotoxin (LT) strain of ETEC has antigenic commonalities to the recombinant $\mathrm{B}$ subunit of the cholera toxin in the oral cholera/ETEC-diarrhea vaccine (Dukoral). ${ }^{7-10}$ The vaccine is promoted in Canada to protect travellers against TD but may provide a false sense of security, as the actual efficacy of this vaccine for the prevention of allcause TD is quite low, at only $6 \% .{ }^{6,7}$ More evidence is required to definitively recommend this vaccine even in those high-risk travellers where TD can be more serious. ${ }^{6,7}$ A recent review found insufficient evidence to recommend this vaccine in $\mathrm{TD}$ prevention, citing a need for further research to create a vaccine to cover all antigenic variations of ETEC. ${ }^{11}$

Travellers' perceptions and preferences can be considered when discussing this vaccine. ${ }^{6,12}$ To reduce their perceived risk of TD, travellers may be willing to pay close to $\$ 100 \mathrm{CAN}$ for a vaccine with minimal efficacy. ${ }^{6,10}$ TD self-management should still be reinforced for possible diarrheal illness during travel. Consult the Committee to Advise on Tropical Medicine and Travel (CATMAT) guidelines for TD prevention and management for additional guidance. ${ }^{6}$

General access to sanitary conditions for most travellers creates a very low risk of infection with Vibrio cholerae O1 $(0.01 \%-0.001 \% /$ month of stay in risk areas), with most cases being mistaken for self-limiting bouts of TD. ${ }^{13-15}$ The use of the oral cholera/ETEC-diarrhea vaccine has shown to have high short-term (6 months) protection against V. cholera O1 at $85 \%$ to $90 \%$, but over 3 years only an average of $63 \%$ efficacy as protection drops to $<50 \%$ after the first year. ${ }^{13-15}$ Booster doses given within 2 years have shown to provide anamnestic

\footnotetext{
This series of articles has been accredited for 1.75 CEUs under CCCEP file \#: 8002-2019-2888-I-P. To earn your CEUs, please review each article, then click on www.pharmacists.ca/immunizers to complete a series of short assessments.
} 
PHARMACISTS AS IMMUNIZERS

TABLE 1 Travel vaccine update and summary

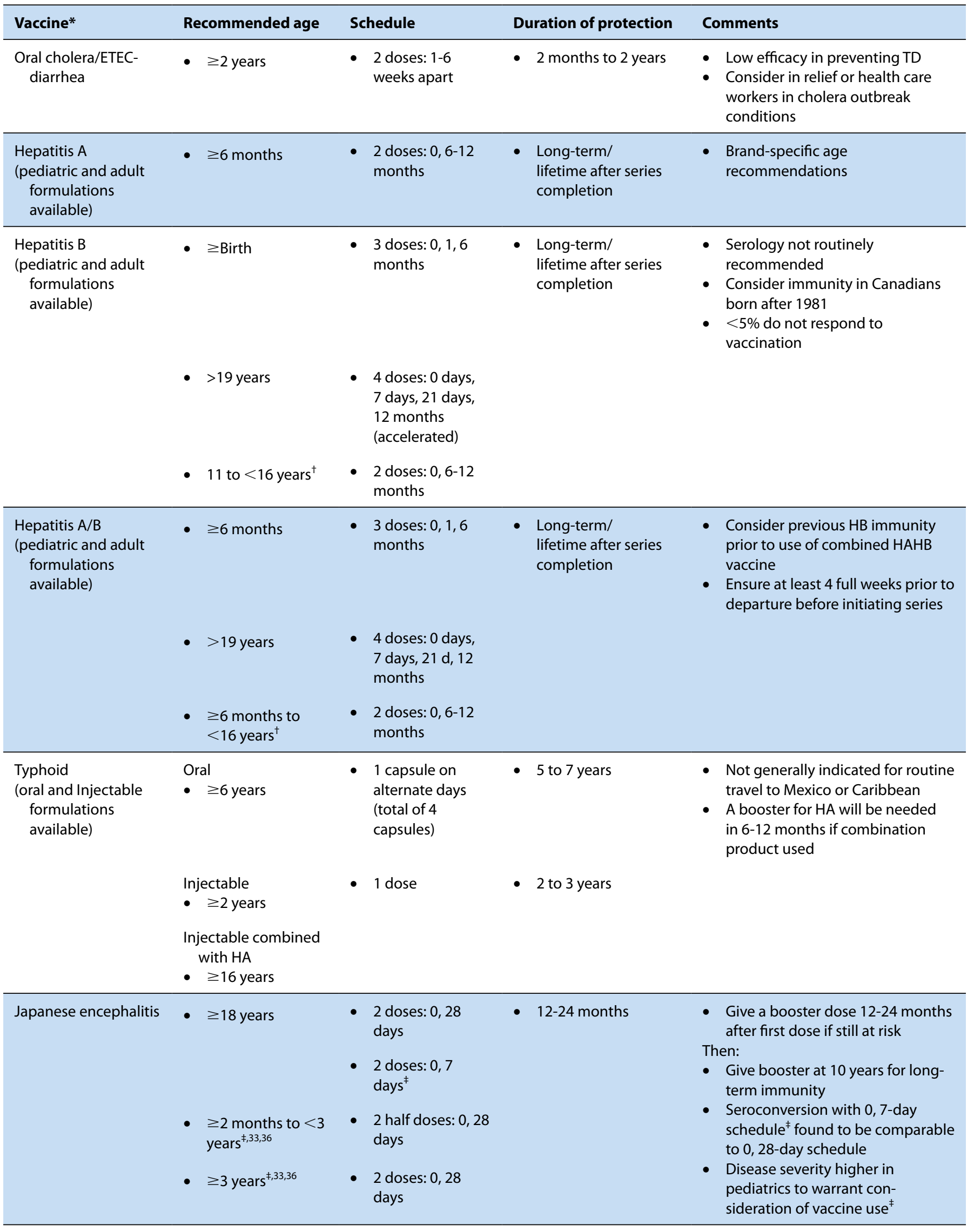


TABLE 1 (continued)

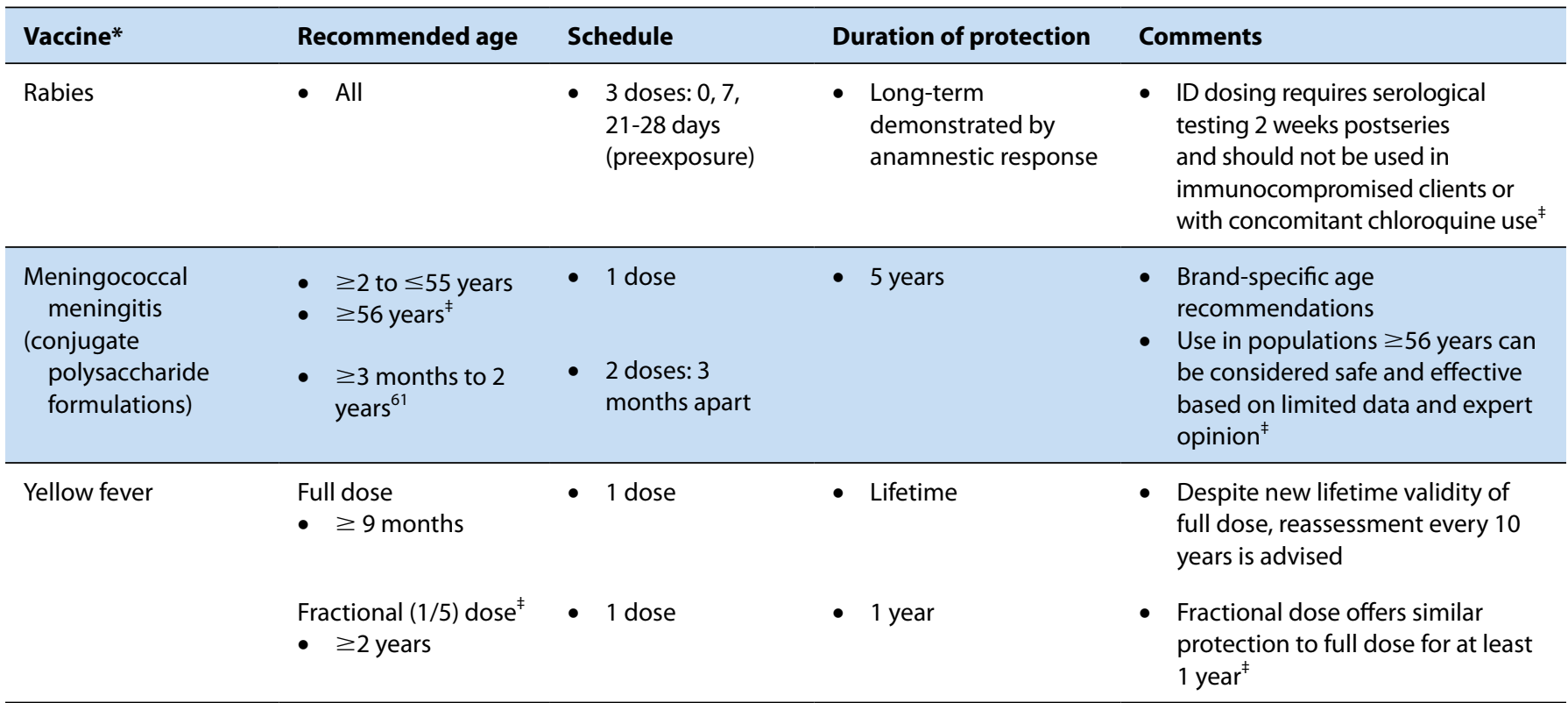

ETEC, Escherichia coli; $\mathrm{HA}$, hepatitis A; $\mathrm{HAHB}$, hepatitis A and B vaccine; $\mathrm{HB}$, hepatitis B; ID, intradermal; TD, travellers' diarrhea.

*Providers should refer to the Canadian Immunization Guide and product monographs for complete indications for clinic use, age-specific dosing schedules and contraindications.

${ }^{\dagger}$ Alternate pediatric dose using the adult formulation.

"Considered an "off-label" use.

(memory-based) response, but that effect is lost after 2 years and the series should be restarted if at risk beyond this time. ${ }^{7}$

Use of this vaccine for cholera is generally reserved for populations at high risk of exposure in endemic or epidemic conditions. ${ }^{14}$ Travellers providing relief work and/or medical care to displaced persons (e.g., refugee camps or disaster relief) should be considered for vaccination against cholera. ${ }^{7,14,16}$ of note, the commercially available preparation in Canada does not protect against $V$. cholera O139, most commonly found in India and Bangladesh. ${ }^{14}$

The oral vaccine can be used in patients $\geq 2$ years and is available at pharmacies without a prescription in all provinces (except Quebec, where a prescription is required). The vaccine should be completed at least 1 week prior to travel and consists of 2 doses taken 1 to 6 weeks apart, with booster dose(s) required for subsequent travel. ${ }^{6,17}$

\section{Hepatitis A vaccine}

Hepatitis A virus (HAV) is one of the most common infections acquired by travellers. Infection risk and travel are strongly correlated, with $44 \%$ to $55 \%$ of reported hepatitis A (HA) infections in Canada associated with international travel. ${ }^{15,18}$ Vaccine efficacy is high, even with a single dose, and reported $97 \%$ to $100 \%$ seroconversion with the second dose confers long-term protection. ${ }^{15,18}$ HA vaccines (Avaxim; Havrix) are generally considered safe and well tolerated. ${ }^{15}$

HA vaccine should be recommended to all nonimmune travellers to endemic areas as soon as travel is considered and can be started as late as the day of travel and still be effective. ${ }^{19}$ While risk of severe infection is low in infants $\leq 12$ months of age, vaccination with HA vaccine can be given safely, with comparable immunogenicity to those vaccinated $\geq 12$ months of age. For infants travelling to areas with endemic HAV (including Canadian-born children of new Canadian parents), vaccination can be provided beginning at 6 months of age, a recommendation supported by the National Advisory Committee on Immunization. ${ }^{15,18,20}$

\section{Hepatitis $B$ vaccine}

Hepatitis B (HB) vaccine (Engerix B; Recombivax $\mathrm{HB}$ ) was introduced into the universal school-based vaccination program in Canada in 1987 and is also included in routine vaccine schedules in many other countries-this is an important consideration when travellers present for travel health advice. ${ }^{21,22}$ For example, in Alberta, any individual born in 1981 or later would have been eligible to receive the vaccine from the public health vaccination program. ${ }^{23}$ Provincially varying schedules can create some confusion, but a published schedule by province is available. ${ }^{24}$

Canadian-born children travelling to countries with high endemnicity of hepatitis B virus (HBV) with their Canadian immigrant parents to visit friends and relatives are at high risk of exposure and should be vaccinated if they were not given the vaccine in infancy. ${ }^{25}$ Any nonimmune individual travelling to endemic countries, with any potential for possible exposure to blood or bodily fluids, should be vaccinated against $\mathrm{HBV}^{26}$ 
For most, completion of a 3- to 4-dose series of $\mathrm{HB}$ vaccine confers long-term or lifetime immunity. ${ }^{25}$ Vaccine nonresponse does occur ( $<5 \%$ of those vaccinated) and a repeated series should be completed, along with serology 1 to 2 months after the last dose. Negative serology after the repeated series confirms nonresponse, and those individuals should be counselled on strict risk avoidance and postexposure follow-up. ${ }^{27}$ Travellers with chronic renal disease or immunodeficiency should receive a series using double doses of the appropriate formulation of $\mathrm{HB}$ vaccine, along with serology 1 to 2 months after series completion. ${ }^{25}$ Neither booster doses nor routine serology are routinely recommended in immunocompetent individuals. Despite low or undetectable titers, cell-mediated immune memory persists. ${ }^{25}$

\section{Combined hepatitis $A$ and $B$ vaccine}

At times, travellers request specific vaccines, including the well-advertised combined hepatitis A and B vaccine (HAHB) vaccine (Twinrix). Time remaining before travel and previous $\mathrm{HB}$ vaccination status are important considerations. Previous $\mathrm{HB}$ vaccine recipients would only need to update HA. For those with no $\mathrm{HB}$ vaccine history, if there is insufficient time to ensure at least 2 to 3 doses within 3 to 4 weeks, it is recommended to administer the monovalent vaccines for HA and HB separately. ${ }^{19}$ Knowledge of alternate dosing schedules can ensure the protection of travellers during supply restraints. For example, adult HAHB vaccine can be used in pediatrics (1-15 years of age) as a 0,6 -month schedule. ${ }^{25}$ Recommended agedependent dosing schedules and available brands can be found by reviewing the Canadian Immunization Guide. ${ }^{15,25}$

\section{Typhoid vaccine}

Available vaccines against the fecal-oral transmission of Salmonella typhi have only moderate efficacy, ranging from $50 \%$ to $70 \%$. Vaccination is indicated for travellers visiting those areas of highest risk found in South Asia and can be considered in areas of Southeast Asia and Africa for travellers with higher-risk itineraries (e.g., backpacking and long duration of travel). Because of the low risk of typhoid in South America, the Caribbean and Mexico, typhoid vaccines are not usually indicated. ${ }^{28-30}$ Risk factors for typhoid disease include longer duration of travel, achlorhydria, travellers visiting friends and relatives, rural itineraries and adventurous eating habits. ${ }^{28-30}$ These, as well as patient preference, cost and frequency of travel, should be taken into account when recommending typhoid vaccine and when choosing a dosage form. ${ }^{29}$

A single dose of injectable typhoid vaccine (Typh-I) or injectable typhoid vaccine combined with HA (HA-Typh-I) will confer protection for 2 to 3 years, and oral typhoid (TyphO) given as 4 capsules on alternate days will confer immunity for approximately 5 to 7 years. ${ }^{28,31}$ Both the injectable and oral vaccines are generally safe and well tolerated and considered protective within 7 to 10 days after vaccination. ${ }^{30}$ Three commercially available vaccines are available for typhoid fever in Canada: Typh-I (Typhim-Vi), HA-Typh-I (Vivaxim) and Typh-O (Vivotif). ${ }^{30}$

\section{Japanese encephalitis vaccine}

Japanese encephalitis virus (JEV) is a Flavivirus common in many Asian countries, where it is considered a public health issue requiring routine vaccination. ${ }^{32}$ The night-biting Culex mosquito transmitting JEV breeds in large pools of water, including areas in which flood irrigation is practiced, such as rice fields. The risk for travellers is considered low but risk increases based on duration of travel, location, season and planned activities during travel. While most cases are asymptomatic (making the reported incidence lower than the actual incidence), the case fatality rate is reported to be $20 \%$ to $30 \%$, with long-term neurological sequelae reported in as high as $50 \%$ of survivors. ${ }^{32-34}$ Pharmacists recommending this vaccine should have a good knowledge of seasonal variances in risk based on geographic climate. ${ }^{31,35}$

The vero cell JEV vaccine JEV-VC (Ixiaro), available in Canada, has shown favourable response. Although actual overall prevention rates are not known, it is assumed that protection can be expected when combined with strict personal protective measures based on the presence of antibodies in at least $95 \%$ of vaccinees a month after vaccination with 2 doses 28 days apart. ${ }^{34}$

In Canada, JEV-VC vaccine has been approved for use in adults $\geq 18$ years using a dose on day 0 and day 28 . Boosters at 12 to 24 months have been recommended for travellers still at risk of exposure, and a single booster at 10 years has been proposed to confer long-term or lifetime immunity. ${ }^{32}$ Recently, JEV-VC has been approved for use in the United States in children $\geq 2$ months of age (half a dose recommended for children aged $\geq 2$ months to $<3$ years) on days $0,28 .{ }^{33,36}$ In Canada, this would still be considered "off-label." However, since safety and efficacy are similar in pediatric and adult populations, the vaccine should be considered for pediatric travellers to endemic areas, as disease severity is high in this population. ${ }^{32,36}$

Last-minute travellers often complicate the travel health assessment process, since ideally, initiation of JEV-VC should occur 6 weeks prior to departure to establish protective antibody levels. Recently, a rapid dosing schedule for adults aged 18 to 65 years has been approved for use in the United States (considered "off-label" in Canada), with a dose on day 0 and day 7 completed at least 1 week before risk of exposure, with seroconversion comparable to the 0 - and 28 -day schedule. . $^{32,37}$

\section{Rabies vaccine}

Rabies exposure from the bite or scratch of an infected mam$\mathrm{mal}$ is a serious event and, if left untreated, is fatal. ${ }^{38}$ Limitations to preexposure vaccination include cost, time to travel and low perception of actual risk. Travellers at higher risk of exposure should be encouraged to vaccinate, including 
travellers visiting friends and relatives (especially young children), expatriates/long-term travellers, travellers engaging in high-risk activities (e.g., cave exploration, animal care) and travellers to high-risk areas with limited or no rabies immune globulin and vaccine. ${ }^{38,39}$

Intramuscular rabies vaccine given on days 0,7 , and 21 or 28 is safe and immunogenic in healthy travellers. ${ }^{40,41}$ Booster doses and serology are not routinely recommended except in those at sustained high risk. Immunity is considered long term, as demonstrated by anamnestic responses to booster doses. ${ }^{41}$ Intradermal (ID) dosing can be used with similar response, but serologic testing should be performed at least 2 weeks postseries if this route is used. While ID use reduces the cost to travellers, the time to vaccinate and obtain serology can exceed 7 weeks. ${ }^{42,43}$ The vial must be used within 6 hours of reconstitution, however, which creates challenges to maximize the number of patients vaccinated to reduce waste..$^{39,40,42,43}$ ID dosing should not be used in immunocompromised travellers or with concomitant chloroquine use. ${ }^{40,43}$

\section{Meningococcal meningitis}

The risk to travellers for acquiring Neisseria meningitidis is low, but implications of infection with invasive meningococcal disease (IMD) are high, with case fatality rates $>10 \% .{ }^{13}$ Approximately $20 \%$ of survivors suffer long-term sequelae, including brain damage, limb loss and hearing and/or learning disabilities. ${ }^{13,44}$ Five serogroups most commonly associated with invasive disease include A, B, C, Y and W-135, and their prevalence will vary by continent. ${ }^{45-47}$ Indications for vaccination of travellers using the quadrivalent meningococcal vaccine (Men-ACYW135) will depend on destination, activities, patient characteristics and host condition. ${ }^{48}$

Conjugate Men-ACYW135 vaccines have shown to be more effective than polysaccharide vaccines, and the 3 available conjugate vaccines (Menveo, Menactra and Nimenrix) can be used interchangeably in travellers between the ages of 2 and 55 years. ${ }^{45,47}$ Available evidence demonstrates that they can also be used (off-label) in those $\geq 56$ years. ${ }^{45}$ Repeated doses are to be given every 5 years if still at risk. ${ }^{45,47}$ Beginning in 2002, proof of vaccination with Men-ACYW135 is required for all those wanting to enter Saudi Arabia for Hajj and Umrah pilgrimages. ${ }^{45,46,49}$ Vaccination with the conjugate vaccine is preferred and should occur within 3 years to 10 days before entry into the country. ${ }^{45,48}$

Available vaccines and their schedules (including for travellers $<2$ years) can be found in the Canadian Immunization Guide. $^{47}$

\section{Yellow fever vaccine}

Yellow fever (YF) is a Flavivirus transmitted by day-biting Aedes or Haemagogus mosquitos, with a 3- to 6-day incubation period, and is endemic and intermittently epidemic in Africa and South America. ${ }^{50,51}$ Risk to travellers varies by destination and season and can be difficult to quantify. In severe infections, fatality rates are high, even with aggressive supportive treatments. ${ }^{51}$ In addition to personal protective measures, vaccination should be considered in certain travellers after performing a thorough risk assessment. Risk of severe adverse vaccine reactions should be weighed with actual risk of disease vs entry requirements, and travellers with absolute contraindications should not be vaccinated. ${ }^{50,51}$ Protection after vaccination is to be considered lifetime and boosters not recommended except for travellers visiting areas with current outbreaks or those who are HIV positive if it has been $>10$ years since their primary dose. $^{52}$

YF vaccination and official documentation must be received at designated YF vaccination centres, which are becoming more prevalent in Canada. ${ }^{53}$ Pharmacies can become designated centres, provided they specify a nominated health care practitioner with prescribing authority to ensure requirements are met. ${ }^{54}$ Notably, recent YF vaccine supply restraints have limited vaccine accessibility to travellers. ${ }^{4}$ However, in 2017, Health Canada supported the use of fractional dosing of YF vaccine to extend available supply. ${ }^{53,55}$ Using $1 / 5$ the dose has been shown to provide similar protection as a full dose, for at least 1 year. ${ }^{55}$

Consult CATMAT guidelines for using fractional YF dosing. ${ }^{54}$

\section{Pharmacists poised for future expansion of travel vaccination services}

The availability, accessibility and public trust in pharmacists place the profession in a unique position to offer pretravel consultation for patients. ${ }^{4}$ Moreover, recent expansion in scope of pharmacy practice has presented an opportunity for pharmacists to play a larger role in providing vaccination services for travellers in community pharmacies or travel clinics. ${ }^{3}$ Notably, the majority (or all) of the travel vaccines covered in this article fall within current (or pending) scope of practice for pharmacists in most jurisdictions outside of Nunavut and Northwest Territories, where pharmacists do not yet have immunizing authority. ${ }^{56-59}$

A recent study conducted in Alberta has demonstrated positive patient health status and high satisfaction (94\%) with care received following a pretravel consultation at a pharmacist-managed travel clinic. ${ }^{4}$ In this study, a total of 280 vaccines were recommended across 103 study participants, with the vast majority (79\%) of these vaccines administered in the clinic. These results provide evidence to support continued expansion of pharmacists' scope in pretravel health, including vaccination, and suggest the need for future efforts to expand advanced training in travel medicine. Ultimately, pharmacybased delivery of travel vaccines promises to improve patient access to recommended vaccines, thereby protecting travellers' health and potentially reducing the global burden of infectious disease. ${ }^{60}$ 
From the Travel Health Network: Vaccination Clinic and Consultants, St. Albert, Alberta. Contact christina@travelhealthnetwork.com.

ORCID iD: Christina Bascom (iD https://orcid.org/0000-0002-1312-7858

\section{References}

1. World Tourism Organization (WTO). UNWTO tourism highlights 2017. Available: https://www.e-unwto.org/doi/pdf/10.18111/9789284419029 (accessed Jan. 5, 2019).

2. Schellack N, van der Sandt N, Modau T, Pople T, Meyer JC. Travel vaccines: information for health practitioners. S Afr Pharm J 2016;83(10):17-26.

3. Bascom CS, Rosenthal MM, Houle SKD. Are pharmacists ready for a greater role in travel health? An evaluation of the knowledge and confidence in providing travel health advice of pharmacists practicing in a community pharmacy chain in Alberta, Canada. J Travel Med 2015;22(2):99-104.

4. Houle SKD, Bascom CS, Rosenthal MM. Clinical outcomes and satisfaction with pharmacist-managed travel clinic in Alberta, Canada. Travel Med Infect Dis 2018;23:21-26.

5. Ray C. Drug, vaccine shortages likely to continue, warns N.S. pharmacy association. February 1, 2019. Available: https://www.cbc.ca/news/canada/novascotia/drug-vaccine-shortages-likely-to-continue-1.5000854 (accessed Apr. 11, 2019).

6. Public Health Agency of Canada. Statement on international travellers diarrhea: an advisory committee statement (ACS) committee to advise on tropical medicine and travel (CATMAT). Available: https://www.canada.ca/en/public-health/ser vices/catmat/statement-travellers-diarrhea.html (accessed Apr. 11, 2019).

7. Public Health Agency of Canada. Canadian Immunization Guide. 2017. Cholera and enterotoxigenic Escherichia coli (ETEC) travellers' diarrhea vaccine. Available: https://www.canada.ca/en/public-health/services/publicat ions/healthy-living/canadian-immunization-guide-part-4-active-vaccines/ page-3-cholera-enterotoxigenic-escherichia-coli-travellers-diarrhea-vaccine .html (accessed Apr. 28, 2019).

8. Shah N, Dupont HL, Ramsey DJ. Global etiology of travelers' diarrhea: systematic review from 1973 to the present. Am J Trop Med Hyg 2009;80(4):609-14. 9. Centers for Disease Control and Prevention. Travelers' diarrhea. Available: https://wwwnc.cdc.gov/travel/yellowbook/2018/the-pre-travel-consultation/ travelers-diarrhea (accessed Apr. 28, 2019).

10. Hasle G, Heier L. How low an effect of a preventative measure against diarrhea are travellers willing to pay for? A survey of Norwegian travellers. Travel Med Infect Dis 2016;14:621-4.

11. Ahmed T, Bhuiyan TR, Zaman K, Sinclair D, Qadri F. Vaccines for preventing enterotoxigenic Escherichia coli ETEC diarrhea (review). Cochrane Database Syst Rev 2013;7:i-93.

12. Lundkvist J, Steffan R, Jönsson B. Cost-benefit of $\mathrm{WC} / \mathrm{rBS}$ oral cholera vaccine for vaccination against ETEC-caused travelers' diarrhea. J Travel Med 2009;16(1):28-34.

13. Steffen R, Behrens RH, Hill DR, Greenaway C, Leder K. Vaccine-preventable travel health risks: what is the evidence-what are the gaps? J Travel Med 2014;22(1):1-12.

14. Torresi J, Kollaritsch H. Recommended/required travel vaccines. In: Keystone JS, Kozarsky PE, Conner BA, Nothfurt HD, Mendelson M, Leder K, editors. Travel medicine. 4th ed. Edinburgh: Elsevier; 2019. p. 101-24.

15. Public Health Agency of Canada. Canadian Immunization Guide. 2018. Hepatitis A vaccine. Available: https://www.canada.ca/en/public-health/ser vices/publications/healthy-living/canadian-immunization-guide-part-4-act ive-vaccines/page-6-hepatitis-a-vaccine.html (accessed Dec. 18, 2018).
16. Travax Shoreland. Cholera. Available: https://travax.com/library/cholera (accessed Jul. 19, 2019).

17. Updated indication for Dukoral ${ }^{\circ}$ travel vaccine: as Canadians take a budgetconscious approach to tropical destinations in 2016, enterotoxigenic E. coli is a growing health risk. Press release, May 9, 2017. Available: https://www.valneva .ca/media/Press_releases/News_release_Dukoral_April_29_FINAL_Layout _EN.pdf (accessed Apr. 28, 2019)

18. Public Health Agency of Canada. An advisory committee statement (ACS) National Advisory Committee on Immunization (NACI). Update on the recommended use of hepatitis a vaccine. Available: https://www.canada.ca/en/ public-health/services/publications/healthy-living/update-recommendeduse-hepatitis-vaccine.html (accessed Dec. 18, 2018).

19. Public Health Agency of Canada. Summary of recommendations for the prevention of viral hepatitis during travel. CCDR 2014;40(13):278-81.

20. Travax Shoreland. Hepatitis A. Available: https://www.travax.com/library/ hepatitis-a (accessed Dec. 18, 2018).

21. Canadian Public Health Association. Immunization timeline. Available: https://www.cpha.ca/immunization-timeline (accessed Jan. 5, 2019).

22. Mackell SM, Starr M. Pediatric travel vaccinations. In: Keystone JS, Kozarsky PE, Conner BA, Nothfurft HD, Mendelson M, Leder K, editors. Travel medicine. 4th ed. Edinburgh: Elsevier; 2019. p. 125-37.

23. Alberta Health Services. Hepatitis B vaccine biological page. Available: https://www.albertahealthservices.ca/assets/info/hp/cdc/if-hp-cdc-hep-bvac-bio-pg-07-234.pdf (accessed Dec. 21, 2018).

24. Public Health Agency of Canada. Canada's provincial and territorial routine (and catch-up) vaccination routine schedule programs for infants and children. Available: https://www.canada.ca/en/public-health/services/provincial-terri torial-immunization-information/provincial-territorial-routine-vaccinationprograms-infants-children.html (accessed Dec. 21, 2018).

25. Government of Canada. Canadian Immunization Guide. Hepatitis B vaccine. Available: https://www.canada.ca/en/public-health/services/publicat ions/healthy-living/canadian-immunization-guide-part-4-active-vaccines/ page-7-hepatitis-b-vaccine.html (accessed Dec. 21, 2018).

26. Travax Shoreland. Hepatitis B. Available: https://www.travax.com/library/ hepatitis-b (accessed Dec. 21, 2018).

27. Centers for Disease Control and Prevention. The pink book. Hepatitis B. Available: https://www.cdc.gov/vaccines/pubs/pinkbook/hepb.html (accessed Dec. 21, 2018).

28. Travax Shoreland. Typhoid. Available: https://www.travax.com/library/ typhoid (accessed Jan. 5, 2019).

29. Public Health Agency of Canada. Statement on international travellers and typhoid: an advisory committee statement (ACS) committee to advise on tropical medicine and travel (CATMAT). Available: http://publications.gc.ca/site/ eng/460371/publication.html (accessed Jan. 5, 2019).

30. Public Health Agency of Canada. Canadian Immunization Guide. 2018. Typhoid vaccine. Available: https:/www.canada.ca/en/public-health/services/ publications/healthy-living/canadian-immunization-guide-part-4-active-vac cines/page-23-typhoid-vaccine.html (accessed Jan. 5, 2019).

31. Myers AL, Christenson JC. Approach to immunization for the travelling child. Infect Dis Clin N Am 2015;29:745-57. 
32. Amicizia D, Zangrillo F, Lai PL, Iovine M, Panatto D. Overview of Japanese encephalitis disease and its prevention: focus on IC51 vaccine (Ixiaro ${ }^{\circ}$ ). J Prev Med Hyg 2018;59:E99-E107.

33. Centers for Disease Control and Prevention. Use of Japanese encephalitis vaccine in children: recommendations of the advisory committee on immunization practices, 2013. MMWR Morb Mortal Wkly Rep 2013;62(45):898-900. 34. Public Health Agency of Canada. An advisory committee statement (ACS) committee to advise on tropical medicine and travel (CATMAT). Statement on protection against Japanese encephalitis. Available: https://www.canada.ca/en/ public-health/services/reports-publications/canada-communicable-diseasereport-ccdr/monthly-issue/2011-37/canada-communicable-disease-reportacs-1.html (accessed Jan. 5, 2019).

35. Travax Shoreland. Thailand. Available: https://www.travax.com/destinat ions/thailand (accessed Jan. 10, 2019).

36. Rebaza A, Lee PJ. One more shot for the road: a review and update of vaccinations for pediatric travellers. Pediatr Ann 2015;44:e89-96.

37. Centers for Disease Control and Prevention. Last minute travellers. Available: https://wwwnc.cdc.gov/travel/yellowbook/2018/advising-travelers-withspecific-needs/last-minute-travelers (accessed Jan. 5, 2019).

38. Centers for Disease Control and Prevention. Rabies. Available: https:// wwwnc.cdc.gov/travel/yellowbook/2018/infectious-diseases-related-totravel/rabies (accessed Jan. 9, 2019).

39. Public Health Agency of Canada. An advisory committee statement (ACS) committee to advise on tropical medicine and travel (CATMAT). Statement on travellers and rabies vaccine. Available: http://publications.gc.ca/collections/ Collection/H12-21-2-28-4.pdf (accessed Jan. 9, 2019).

40. Public Health Agency of Canada. Canadian Immunization Guide. Rabies vaccine. Available: https://www.canada.ca/en/public-health/services/publica tions/healthy-living/canadian-immunization-guide-part-4-active-vaccines/ page-18-rabies-vaccine.html (accessed Jan. 5, 2019).

41. World Health Organization (WHO). Weekly epidemiolocal record. Rabies vaccines: WHO position paper-April 2018. Available: http://apps.who.int/iris/ bitstream/handle/10665/272371/WER9316.pdf?ua=1 (accessed Jan. 9, 2019). 42. Kong LY, Vincelette J, Laplante G, Duchesne J, Libman M, Barkati S. Intradermal pre-exposure rabies vaccination in a Canadian travel clinic: 6-year retrospective observational study. CMAJ Open 2018;6(2):E168-75.

43. Centers for Disease Control and Prevention. Perspectives: intradermal rabies preexposure immunization. Available: https://wwwnc.cdc.gov/travel/ yellowbook/2018/infectious-diseases-related-to-travel/perspectives-intrader mal-rabies-preexposure-immunization (accessed Jan. 9, 2019).

44. Black S. Travelers' protection against meningococcal disease: a new vaccine option. J Trav Med 2010;17(Suppl 1):18-25.

45. Public Health Agency of Canada. CATMAT statement: meningococcal disease and the international traveller. Available: https:/www.canada.ca/en/ public-health/services/reports-publications/canada-communicable-diseasereport-ccdr/monthly-issue/2015-41/ccdr-volume-41-05-may-7-2015/ccdrvolume-41-05-may-7-2015-1.html (accessed Jul. 19, 2019).

46. Centers for Disease Control and Prevention. Meningococcal disease. Available: https://wwwnc.cdc.gov/travel/yellowbook/2020/travel-related-infecti ous-diseases/meningococcal-disease (accessed Jul. 17, 2019).

47. Public Health Agency of Canada. Canadian Immunization Guide. 2018. Meningococcal vaccine. Available: https://www.canada.ca/en/public-health/ services/publications/healthy-living/canadian-immunization-guide-part4-active-vaccines/page-13-meningococcal-vaccine.html (accessed Jul. 17, 2019).

48. Steffen R. The risk of meningococcal disease in travelers and current recommendations for prevention. J Travel Med 2010;17(Suppl 1):9-17.

49. Wilder-Smith A, Steffen R. Mass gatherings. In: Keystone JS, Kozarsky PE, Conner BA, Nothfurt HD, Mendelson M, Leder K, editors. Travel medicine. 4th ed. Edinburgh: Elsevier; 2019. p. 383-6.

50. Centers for Disease Control and Prevention. Yellow fever. Available: https:// wwwnc.cdc.gov/travel/yellowbook/2018/infectious-diseases-related-totravel/yellow-fever (accessed Jan. 9, 2019).

51. Public Health Agency of Canada. An advisory committee statement (ACS) committee to advise on tropical medicine and travel (CATMAT). Statement for travellers and yellow fever. Available: https://www.canada.ca/en/public-health/ services/reports-publications/canada-communicable-disease-report-ccdr/ monthly-issue/2013-39/statement-travellers-yellow-fever.html (accessed Jan. 9, 2019).

52. Public Health Agency of Canada. An advisory committee statement (ACS) committee to advise on tropical medicine and travel (CATMAT). Statement of the use of booster doses of yellow fever vaccine. Available: https://www.canada .ca/en/public-health/services/publications/diseases-conditions/use-boosterdoses-yellow-fever-vaccine.html (accessed Jan. 9, 2019).

53. Zimmer R. Competing visions for travel health services in Canada. J Trav Med 2018;25(1):1-3.

54. Public Health Agency of Canada. Procedures for yellow fever vaccination centres in Canada. Available: https://www.canada.ca/en/public-health/ser vices/travel-health/yellow-fever/procedures-yellow-fever-vaccination-cen tres-canada.html (accessed Apr. 28, 2019).

55. Public Health Agency of Canada. An advisory committee statement (ACS) committee to advise on tropical medicine and travel (CATMAT). Interim Canadian recommendations for the use of fractional dose of yellow fever during a vaccine shortage. Available: https://www.canada.ca/en/public-health/services/ publications/diseases-conditions/interim-recommendations-fractional-doseyellow-fever-vaccine-shortage.html (accessed Jan. 9, 2019).

56. Canadian Pharmacists Association. Pharmacists' expanded scope of practice, April 2019. Available: https://www.pharmacists.ca/pharmacy-in-canada/ scope-of-practice-canada/ (accessed May 1, 2019).

57. Houle S. Improving access to travel vaccines: the pharmacist's role. Canadian immunization conference (CIC) presentation, December 4, 2018, Ottawa. Available: http://cic2018.isilive.ca/presentation/248 (accessed Apr. 28, 2019).

58. Morin P. New rules will let Yukon pharmacists deliver vaccines. May 29, 2019. Available: https://www.cbc.ca/news/canada/north/new-rules-yukonpharmacists-1.5153231 (accessed Jul. 19, 2019).

59. CTV News. Montreal, Quebec pharmacists get new powers to prescribe, vaccinate. June 12, 2019. Available: https://montreal.ctvnews.ca/quebec-pharm acists-get-new-powers-to-prescribe-vaccinate-1.4463586 (accessed Jul. 19, 2019).

60. Houle SK. Pharmacy travel health services: current perspectives and future prospects. Integr Pharm Res Pract 2018;23(7):13-20.

61. Pfizer Canada. Nimenrix product monograph. Available: https:// www.pfizer.ca/sites/g/files/g10050796/f/201901/Nimenrix_PM_ NC_220188_19Dec2018_E.pdf (accessed Jul. 19, 2019). 